\section{$\underset{\substack{\text { hommes } \\ \text { \& migrations }}}{ }$}

\section{Hommes \& migrations}

Revue française de référence sur les dynamiques

migratoires

1307 | 2014

L'Afrique qualifiée dans la mondialisation

\title{
Damien Roudeau, Villiers Rebelle. [Carnet de rencontres] à la Cerisaie,
}

Antony, La Boîte à bulles, 2014, $22 €$.

\section{Mustapha Harzoune}

\section{(2) OpenEdition}

Journals

Édition électronique

URL : http://journals.openedition.org/hommesmigrations/2970

DOI : $10.4000 /$ hommesmigrations.2970

ISSN : 2262-3353

Éditeur

Musée national de l'histoire de l'immigration

Édition imprimée

Date de publication : 1 juillet 2014

Pagination : 209

ISBN : 978-2-919040-28-5

ISSN : 1142-852X

Référence électronique

Mustapha Harzoune, «Damien Roudeau, Villiers Rebelle. [Carnet de rencontres] à la Cerisaie, »,

Hommes \& migrations [En ligne], 1307 | 2014, mis en ligne le 15 janvier 2015, consulté le 22 septembre 2020. URL : http://journals.openedition.org/hommesmigrations/2970 ; DOI : https://doi.org/10.4000/ hommesmigrations. 2970

Ce document a été généré automatiquement le 22 septembre 2020.

Tous droits réservés 


\title{
Damien Roudeau, Villiers Rebelle. [Carnet de rencontres] à la Cerisaie,
}

Antony, La Boîte à bulles, 2014, $22 €$.

\author{
Mustapha Harzoune
}

\section{RÉFÉRENCE}

Mehdi Lallaoui, Les Poilus d'ailleurs,

Paris, Au nom de la mémoire, 2014, 139 pages.

1 Villiers Rebelle est un reportage tout en dessins réalisé à la Cerisaie, cité de Villiers-leBel, dans le cadre d'un projet de rénovation urbaine. La Cerisaie, c'est trois bâtiments Acacias, Bleuets et Clématites - sortis de terre en 1958, que l'on tente de réhabiliter depuis 2004 pour deux d'entre eux, le troisième, les Clématites, ayant été détruit le 26 août 2013. Avec les poussières de la démolition se sont envolés les traces et les souvenirs d'existences condamnées à l'oubli. Ici vivent plusieurs centaines d'hommes et de femmes, plutôt jeunes, immigrés ou d'origine; une population frappée par le chômage, comprimée dans des logements exigus et délabrés, coincée par une sédentarisation forcée. La relégation à dix-huit kilomètres de la Ville-Lumière. Un quotidien boiteux agité d'émeutes comme autant de soubresauts de souffreteux qui refusent de mourir. Comme en novembre 2007, après la mort de deux adolescents à moto, percutés par une voiture de police. Ça a chauffé, et la Cerisaie en fut. À l'arrivée : une école, une bibliothèque, un commissariat, une agence du Trésor public, un concessionnaire, une auto-école, un salon de beauté et un supermarché sont partis en fumée ! Rien moins...

Damien Roudeau - Prix de l'écriture et Grand prix du Rendez-vous du carnet de voyage de Clermont-Ferrand en 2006 pour De bric et de broc - a passé trois ans in situ. Il y a animé des ateliers de dessin de 2010 à 2013, à raison de quelques jours par mois et de rares nuits à l'hôtel mitoyen, l'obscurité étant réservée à "la vie des marges". "Je n'ai pas particulièrement cherché à y avoir accès, respectant le vœu des habitants de porter le focus 
ailleurs, écrit l'auteur-dessinateur. Quelques dessins pour simplement rappeler que derrière les murs on vit, et on y est même souvent heureux." Exit aussi les interrogations sur les reculs de la mixité - on est souvent entre mecs ici.

Le reportage mêle repères historiques et urbains, photos, citations de rappeurs et, bien sûr, dessins, croquis, fresques et autres portraits. Du dessin-journalisme de précision qui ajoute la tendresse du trait pour les hommes et les femmes rencontrés. Acteurs du lieu et cornacs d'un jour rythment le récit. Il y a là, entre autres, Kevin Labrana de l'association Jump, dont le but est de permettre aux jeunes du quartier de sortir, "de voir autre chose que les bâtiments"; Meryem Yettefti et Véronique Baessa, animatrices à la maison de quartier Allende; Bafa et Kalala du duo Versatile, descendants d'une longue lignée de rappeurs sortis des Bleuets, à commencer par le groupe Ärsenik. Le rap, poésie du bitume, transporte ses valises de réalisme et sa charge de contestation. "C'est nous, les rappeurs, les journalistes: on raconte les choses vues, vécues et entendues au sein de notre cité, de notre communauté qui souffre. (...) On raconte sans être des balances. Les tenants du pouvoir ont compris que le rap pouvait être une véritable contre-culture", dit Tekila. Daniel Asif, propriétaire d'un $\mathrm{F} 4,55$ ans et d'origine pakistanaise, a fait de son garage un salon de thé ouvert à tous. Au pied des Clématites, les Pakistanais organisent des tournois de "shooting volleyball" et initient les plus jeunes au cricket. Quant à Chantal Djedde, elle morigène de solides gaillards et des costauds revêches : "Ils font leurs racailles... moi je les appelle toujours mes bébés!"

4 Les planches du premier atelier de dessin où se retrouvent une dizaine de gamins reflètent l'énergie, la pêche, la créativité aussi, de cette jeunesse à l'insolence parfois bienveillante : "Monsieur, faut vous remettre au sport, un peu... Vous êtes greums' la vérité." Plus solennels sont les dessins et portraits du second conseil de quartier où se jouent au quotidien, mais dans l'anonymat médiatique, les bricolages d'une démocratie participative pour trouver "un point de bascule entre les prises de décision par le 'haut' et l'engagement des habitants, par 'en bas"' (version française des empowerment et autres community organizing). Et oui ! Ça bouge, invente, cherche, s'engage, s'organise... bien loin des antiennes sur ces "territoires perdus de la République", une population qui serait amorphe ou une jeunesse "sans repères", comme dirait monsieur Valls. Ici les combats sont nombreux, et difficiles. Sisyphe en abandonnerait son caillou. Mais pas ces hommes et ces femmes qui, parce qu'ils semblent parfois ramer à contre-courant, doivent crier et taper du poing sur la table pour simplement se faire entendre.

\section{AUTEURS}

\section{MUSTAPHA HARZOUNE}

Journaliste 